\title{
A time capsule for patients with dementia?
}

\author{
Robert M Lawrence DMS MRCPsych ${ }^{1}$ Julia H Head BA MTh ${ }^{2}$
}

$J$ R Soc Med 2005;98:116-118

An individual who is approaching the end of a long life will often gain comfort from exploring his or her experiences in emotional and spiritual terms. This is widely recognized, and help is usually at hand for those wishing to address dilemmas relating to religion and values. However, this option will not be available to those who, because of dementia, have lost the ability to communicate on these matters. A caregiver or clinician may fail to grasp the experiences that hold religious and spiritual significance for the patient, and there has been little discussion of how mental health practitioners should address the issue. In this paper we present arguments that lead to the proposal for 'time capsules' whereby patients with early dementia can set down their thoughts and so exercise a degree of control over subsequent events.

\section{CLINICAL APPROACH}

Language is eroded by the process of dementia, and the point comes when normal verbal communication is no longer possible. Health workers then tend to communicate more with caregivers than with the patient. ${ }^{1}$ At this stage the case notes will probably record the patient's cognitive decline and loss of competence in activities of daily living, together with a risk assessment. They may also include reference to the degree of stress being experienced by caregivers and the support they are likely to need. The key elements in care of the patient then follow a mechanistic route of containment and monitoring whilst the focus of emotional and social support switches to the caregiver. This statement is possibly controversial, but few practising clinicians would deny that patient-doctor interaction is eventually lost to care plans. Established practice consists of standardized assessments and a series of practical measures to cope with the onward march of cognitive impairment, neuromotor dysfunction and language dissolution. Feedback from the individual slides into redundancy.

${ }^{1}$ Old Age Psychiatry Research Group, c/o Neurodegeneration Unit, Room 1.126, 1st Floor, Jenner Wing, St George's Hospital Medical School, London SW17 ORE; ${ }^{2}$ Spiritual and Pastoral Care Service, Maudsley Hospital, Denmark Hill, London SE5 8AZ, UK

Correspondence to: Dr R M Lawrence

E-mail: rlawrence@sghms.ac.uk
The final stage of Kübler-Ross's ${ }^{2}$ stages of transition of the dying person is one of acceptance. However, scant attention has been paid to this issue in patients with dementia. Keady and Nolan ${ }^{3}$ describe an eight-stage process through which individuals are assumed to interpret their own early-onset dementia - slipping, suspecting, covering up, revealing, confirming, surviving, disorganization, decline and death. It is notable, that in this theory, 'acceptance' is not mentioned. Whereas the patient with a terminal physical condition might hope to retain capacity and to accept his or her fate, the patient with dementia seems to face nothing but disorganization and decline. Nor is the end mercifully rapid: functions are eroded little by little, over a long period.

A lengthy process, however, should allow more opportunities to negotiate stages leading to final resolution and acceptance. Theory suggests that the successful outcome of this process depends on the personality of the individual, previous coping styles and the pattern of cortical degeneration. ${ }^{4}$ Should clinicians work according to the premise that the individual is lost, or that he or she is attempting to cope in some way? If the latter, how will they seek to preserve the dignity of the individual?

\section{PERSONAL VALUES AND SPIRITUALITY}

Dementia is largely an affliction of the elderly, who are already victims of a western social stereotype that fears the ageing process - a stereotype that conflicts with the spiritual counterpart which associates old age with wisdom and enlightenment. ${ }^{5}$ In holy texts from many faith traditions, the younger generation is exhorted to respect its elders even if the point comes when their bodies and minds falter. Elderly people, in their turn, frequently journey back to their faith and religious practices in search of courage, spiritual healing or atonement and in preparation for death. ${ }^{6-9}$ Such aspirations are linked intrinsically to the individual's personal constructs, context and culture. ${ }^{10,11}$ Recognition of this very human process needs to be taken up in a more focused way in clinical practice. In advanced dementia the neglect of communication extends to aspects of spirituality; and, we would argue, more can be done to surmount the communication boundaries. The proposal offered below is consistent with the reawakening of a mode of clinical practice centred on the uniqueness of the individual person. It allows for the 
exploration of therapeutic possibilities at new levels; ${ }^{12-15}$ and it challenges the clinician to develop skills that, even in advanced dementia, take close account of the patient's individual life-view. ${ }^{16,17}$ Clearly, many clinicians already strive to maintain communication with patients who have lost coherent speech. ${ }^{16,17}$ In our opinion, these skills are enhanced by the self-knowledge that comes from a deliberate exploration of emotions and anxieties around our own ageing and death-a fine-tuning of the sensibilities, coupled with an acquaintance with existing knowledge on the psychology of ageing and dying. In many instances, of course, a caregiver or relative can give valuable indications of the patient's previous persona and life-view. However, in truth there is only one person who can give a proper account of the patient's life story and values - namely, the patient. Only he or she can raise all the desired issues, whether of faith, morality, traditions, love or forgiveness. ${ }^{18}$ The point when this can effectively happen, however, is not at the end of the process of dementia but at the beginning. As the disease advances, the need to reconnect the person to his own integrity will progressively grow. ${ }^{19,20}$ This brings us to our proposal.

\section{THE TIME CAPSULE}

The time capsule, to be prepared from early in the course of dementia, is a personal legacy from and to themselves and for others to refer to when the time comes. The patient will carry this document until meaningful speech is lost and it is handed to caregivers who must interpret the patient's wishes. The time capsule encompasses fundamental themes that offer the possibilities of constant reconnection to self. These might include:

- Individual culture and ethnicity

- Experience of family life, moral and spiritual upbringing, religious and spiritual practice

- Life and death: individual constructs, views on advanced directives and life support, any particular wishes concerning comfort in terminal illness, last rites, funeral arrangements

- Coping style through major life events

- Humanistic inspiration: ideals, art, nature

Even in the initial phases, communication on these topics may not be easy for the patient. He or she may never have consciously considered these themes or may be reluctant to share thoughts on them. Members of the mental health team might apply their special skills to facilitating expression and communication of values. All of this would be in addition to aspects of spiritual assessment that are beginning to be taken up in mental health trusts throughout the UK. The building of a time capsule for the individual, in whatever way it works out in practice, fits in well with the dynamic nature of spirituality. Indeed, where appropriate, people outside the health team such as chaplains might be recruited to help out with this process. The time capsule would accompany the individual from team to team, from home to hospital, from residential to nursing home, to the very end of life.

The aims of the time capsule are to give patients some sense of control in a progressive disorder, to aid caregivers in reconnecting the patient with his disintegrating self and ultimately to give relief and comfort. Could this method be validated? The obstacle, of course, is that dementia will have stolen the principal outcome measures. If scientific proof was unattainable, it might be judged a clinical dead end. The counter-argument is that our proposal is in tune with the bioethical notion on which medicine itself was founded and continues to grow. This is the dignity of human life - the importance of constant regard to individuality and diversity that does not exclude Jews, Christians, Muslims, Buddhists or Hindus, or indeed those with no religion.

\section{REFERENCES}

1 Bush A. Communicating with patients who have dementia. Nursing Times 2003;99:42-5

2 Kübler-Ross E. On Death and Dying. London: Tavistock Publications, 1970

3 Keady J, Nolan M. Younger onset dementia: developing a longitudinal model as a basis for a research agenda and as a guide to interventions with sufferers and carers. J Adv Nursing 1994;19: 659-69

4 Cohen D, Kennedy G, Eisdorfer C. Phases of change in the patient with Alzheimer's Dementia. J Am Geriatr Soc 1984;32:11-15

5 Cheston R, Bender M. Understanding Dementia: the Man with the Worried Eyes. Philadelphia: Jessica Kingsley, 2000

6 Jung K. Modern Man in Search of a Soul. New York: Harcourt Brace Jovanovich, 1933

7 Koenig HG, Kvale JN, Ferrel C. Religion and well being in later life. Gerontologist 1988;28:18-28

8 Post SG, Puchalski CM, Larson DB. Physicians and patient spirituality: professional boundaries, competency and ethics. Ann Intern Med 2000; 132:578-83

9 Shamy E. A Guide to the Spiritual Dimensions of Care for People with Alzheimer's Disease and Related Dementias. More than Body, Brain and Death. London: Jessica Kingsley, 2003

10 Young-Eisendrath P, Miller ME. In: Young-Eisendrath P, Miller ME, eds. The Psychology of Mature Spirituality. London: Routledge, 2000

11 Pargament KJ. The Psychology of Religion and Coping: Theory, Research and Practice. New York: Guilford Press, 1997

12 Kitwood T, Bredin K. Towards a theory of dementia care: personhood and well-being. Ageing Society 1992;12:269-87

13 Kitwood T. Dementia Reconsidered: The Person Comes First. Buckingham: Open University Press, 1997

14 Killick J, Allan K. Communication and the Care of People with Dementia. Buckingham: Open University Press, 2001 
J O U R N L OF THE ROYAL SOCIETY OF MEDICINE Volume 98 March 2005

15 Hockley J, Clark D. Palliative Care for Older People in Care Homes. Buckingham: Open University Press, 2002

16 Lawrence RM. Aspects of spirituality in dementia care: when clinicians tune into silence. Dementia: Int J Soc Res Practice 2003;2:393-404

17 Lawrence RM, Duggal A. Spirituality in old age psychiatry: finding God in confusion. Old Age Psychiatrist 2001;24:4
18 Langle A, Probst C. Existential questions of the elderly. Int Med J 2000;7:193-6

19 Normann HK, Norberg A, Asplund K. Confirmation and lucidity during conversation with a woman with severe dementia. J Adv Nursing 2002;30:370-6

20 Woods RT. Psychological Problems of Ageing. Chichester: John Wiley, 1999 